Beyond these two substances, as absorbents for wound-discharges, he says: "Nothing is really needed. Pads or bags of peat, sawdust, jute, wood-wool, etc., are practically useless."

There are certainly many who do not share in this opinion, for they have found in suitable pads containing sawdust, moss, or similar material, a drcssing not only more easily procured and prepared, more cheap and generally available, but also more certainly absorbent than any kind of prepared cotton.

The subject of anxsthesia occupies a chapter by itself. The use of cocaine for local anresthesia is fully described. For purposes of general anresthcsia, most positive preference is given to ether. All of the objectiors to ether, it is said, fade into insignificance when brought face to face with the fact that about seven lives are sacrificed by chloroform to one by ether. According to the author, chloroform is fast disappcaring in practice. These statements might be questioned by some : there are remote dangers of respiratory disorders and kidney congestions fairly attributable to the use of ether, which in quite a proportion of cases determine delayed fatal results; these deaths, it is possible wiil be charged up to the account of ether by and by, and then possibly the disproportion between the accounts of the two agents will not be so great. At present the jury is divided on the question of ether is. chloroform.

The chapters on Amputations, Aneurisms, and the Ligatures of Arteries are especially good. The illustrations are copious and clear. $\mathrm{By}$ the use of color, the vessels are made exceedingly distinct. It is believed that this is the first time in which this use of color in illustrations of this kind has been made in a surgical text-book.

It is impossible to take up in detail for examination each of the twenty-one chapters of this very interesting book. Its teachings are clear and positive. Its shortcomings, if they be judged such, arc upon the side uf conservatism. As a handbook for the use of students it is unexcelled; its convenient size-less than eight hundred pages of royal octavo, its clear print, its many and excellent illustrations, its practical character, will all combine to commend it to the use of many readers.

\title{
L. S. Pilcher.
}

Transactions of the Americix Surgical Association. Volume IV. Edited by J. Ewivg MIears, MI.D., Recorder of the Association. P. Blakiston, Son \& Co., Philadelphia. is86. 8ro. pp. 240. This volume contains the papers read before the American Surgical 
Association at the meeting held April 28 to May I, I886, together with a report of the discussions upon these papers. The address of the president, Prof. Moses Gunn, on the union of nerves of different function considered in its pathological and surgical relations, opens the volume. This is followed by- $\mathrm{Dr}$. Christopher Johnstou, on Diagnostitial Laparotomy; by Dr. Harold C. Emst, on the Bacteria of Surgical Diseases; by Dr. N. Senn, on the Surgery of the Pancreas ; by Dr. T. F. Prewitt. on Traumatic Aneurism of Internal Carotid Artery following Gunshot Injury; by Dr. Roswell Park, on Lipoma T'estis, and also a report of a Successful Nephrectomy on a patient of twenty-three months; by Dr. W. W. Keen, on Stretching of the Facial Nerve; by Dr. C. 'T. Parkes, on Two Cases of Cholecystotomy; by Dr. C. H. Mastin, on Subcutaneous Division of Urethral Stricture; by Dr. Roswell Park, on An Improved Tracheotomy Tube. The readers of the Ansals of Surgery have already been familiarized with the contents of these papers either by their publication in full in this jour$\mathrm{nal}$, or in abstract in its editorial or index departments. They form a series of papers of great value, which testify to the high character of the association by which they were called out. The range of subjects presented, and the widely separated points of residence of the authors, correspond with the national character of the association. Each annual addition to the series of volumes, in which the transactions of this society are preserved, increases the value of the whole series.

\section{S. Pilcher.}

Handbuch der Chirurgischen Techisi, del Operationex uNd Verdaenden, vos Dr. Aliert vos Mlosetig-Mloorhof, A. O. Professor an der Wiener Univ. etc., mit vielen Abbildungen. $X-X I I$, Lief, Vienna, I886: Toeplitz and Deuticke. (New York: G. E. Stechert). [Handbook of Surgical Technique Pertaining to Operations, Wound-dressings andBandaging].

The final portions of this work, which has been in press since March, I885, are now at hand, treating of operations upon the trunk and on the extremities.

The complete work comprises nearly goo large octavo pages, and is handsomely printed on fine paper. Two hundred and thirty woodcuts, illustrating methods of operating and of bandaging, as well as instruments and appliances, are interspersed in the text.

The object of the author was to provide a book for the use of students and those beginning the practice of surgery, which should present in as concise $a$ form as possible, a description of all operations 